\title{
Subjetividade e imbricamento de linguagens em Yellow Fever, curta de $\mathrm{Ng}^{\prime}$ endo Mukii
}

\author{
Denise Tavares da Silva' \\ https:/orcid.org/0000-0001-5692-7356 \\ I - UFF \\ Niterói (RJ), Brasil
}

Resumo: Em um vídeo de seis minutos, Yellow Fever, a cineasta queniana Ng'endo Mukii entrelaça memória e ativismo, realizando um contundente libelo sobre a violência da imposição de uma beleza definida pelo molde branco-ocidental. Aqui, deslocamos parcialmente este eixo central que mobiliza a obra (pele e raça), focando nossa discussão no processo criativo deste audiovisual. O que nos interessa é problematizar a construção narrativa em chave que discute, além dos aspectos biográficos que fundamentam a obra, também o imbricamento de linguagens, considerado sob o horizonte do entrelaçamento da arte e tecnologia, opção que esgarça as concepções de gênero. Um processo cujo start é a subjetividade que se posiciona no território do levante, da inconformidade e da assunção do protagonismo do audiovisual no espectro midiático globalizado.

Palavras-Chave: audiovisual; Yellow Fever; linguagem; biografia; ativismo.

Abstract: Subjectivity and imbrication of languages in Yellow Fever, short film by $\mathrm{Ng}^{\prime}$ endo Mukii - In a six-minute video, Yellow Fever, the Kenyan filmmaker $\mathrm{Ng}^{\prime}$ endo Mukii interweaves memory and activism, making a forceful libel on the violence of imposing a beauty defined by the Western-white mold. Here, we partially move this central axis that mobilizes the work (skin and race), focusing our discussion on the creative process of this audiovisual. What interests us is to problematize the narrative construction in a key that discusses, besides the biographical aspects that underlie the work, also the overlapping of languages, considered under the horizon of the intertwining of art and technology, an option that cuts across the conceptions of gender. A process whose start is the subjectivity that is positioned in the territory of the uprising, the nonconformity and the assumption of the protagonism of the audiovisual in the globalized media spectrum.

Keywords: audiovisual; Yellow Fever; language; biography; activism.

A primeira versão deste trabalho foi apresentada ao Grupo de Trabalho Comunicação, Arte e Tecnologias da Imagem do XXVIII Encontro Anual da Compós, Pontifícia Universidade Católica do Rio Grande do Sul, Porto Alegre - RS, 11 a 14 de junho de 2019. 


\section{Introdução}

"O que nos subleva?", interroga Didi-Huberman (2017, p. 289), ele mesmo respondendo que "Certamente, são forças, e elas não são exteriores a nós nem impostas: são forças involuídas em tudo o que nos diz respeito mais essencialmente". Uma resposta que só encontra sentido quando desdobra outras interrogações do autor, não só quanto à natureza e forma de tais forças, como também sobre a matriz que as abastecem. Trata-se de um veio fértil que Didi-Huberman percorre, tendo como ponto de partida a perda e a dor, em um percurso que localiza nos gestos humanos a potência da transgressão:

Ser protagonista de um levante é causar ruptura em uma história que o mundo inteiro acreditava entendida (no sentido em que se fala de um caso entendido, fechado, encerrado): é romper a previsibilidade da história, refutar a regra que pensávamos presidir seu desenvolvimento ou sua manutenção (ibidem, p. 310).

Entre outros objetivos, tais movimentos trabalham para romper invisibilidades históricas, ecoando prolíferos caminhos que vão das ruas às artes, em manifestações coletivas e/ou individuais que não se negam às exposições múltiplas e buscam se afirmar em singularidades que nos interessam. Uma delas é a obra da cineasta queniana $\mathrm{Ng}^{\prime}$ endo Mukii $^{2}$, cuja construção fílmica sustenta-se pelo investimento em uma técnica artesã que implica manipulação da imagem - em especial, da fotografia -, com desenhos, rabiscos e cores. Não só: ao conjunto plástico subjaz nas obras a perspectiva do testemunho que se apresenta, quase sempre, entrelaçado à poesia, à música e/ou a vozes, fabulando pungentes vivências e sobrevivências.

Um exemplo contundente destas escolhas é o vídeo Retrato de Marielle Franco, que Mukii realizou com codireção de Paula Callus ${ }^{3}$ e participação de jovens artistas quenianos. Com duração de um minuto e meio, a animação utiliza muitas fotos (especialmente do rosto) da vereadora do PSOL assassinada ${ }^{4}$, que são trabalhadas pictoricamente, reforçando sua identidade afro-brasileira. Estas imagens, somadas às cenas dos protestos (nas ruas) pelo crime, dialogam com uma emocionante e pungente fala ritmada que relembra a dor dos que a perderam e a importância de se preservar a memória e o ativismo de Marielle. A narrativa, portanto, investe na comunhão da sensibilidade e da emoção, buscando irmanar brasileiros e africanos ao universalizar a luta contra as injustiças: “Os jovens artistas

2 Mukii nasceu e permaneceu no Quênia até o ano 2000 quando se mudou para Londres com o objetivo de cursar Design e ser ilustradora. Hoje ela se identifica como cineasta, fotógrafa e escritora e tem morado em diversos lugares, conforme os trabalhos que desenvolve.

3 Disponível em https://vimeo.com/301618386. O vídeo foi produzido em um workshop, atividade do projeto eVoices, em 2018, em Nairobi, Quênia.

4 Marielle Franco, deputada do Partido da Solidariedade (PSOL), foi assassinada em 14 de março de 2018, junto com o motorista que a levava, Anderson Gomes, um crime não esclarecido até o momento de escrita deste texto. Oriunda da Favela da Maré, no Rio de Janeiro, era ativista dos direitos humanos, focando, especialmente, o racismo e o preconceito de gênero. 
ficaram surpresos ao saber que as pessoas estão vivendo uma situação socioeconômica e política semelhante em um lugar do mundo tão diferente. Eles sentiram muito com Marielle e com a causa dela" (MUKII, 2018) $)^{5}$.

Este e outros vídeos de $\mathrm{Ng}^{\prime}$ endo Mukii procuram traduzir o processo investigativo da cineasta. Ela segue o fio de uma trajetória que descobriu na produção audiovisual um espaço de expressão potente para se apresentar e, de certo modo, se constituir como mulher africana. Tal perspectiva evocou interrogações sobre a própria história, localizando as contradições que a desenham e que a cineasta trabalha em Yellow Fever, animação documental e experimental de seis minutos que discutiremos aqui em chave que destaca o papel da subjetividade e do imbricamento de linguagens como definidores dos caminhos narrativos e estéticos da obra. Além disso, nossa abordagem constitui-se, também, do empenho em compreender e/ou localizar se tal processo configura um resultado original que alarga as possibilidades de criação, fruição e percepção do produto audiovisual. Isto é, nossa pretensão não é apresentar a decupagem de cada estratégia narrativa acionada em Yellow Fever, mas sim assumir como ponto de partida o reconhecimento de um eu em constelação, assentado na reafirmação da experiência e no questionamento das normas e regras vivenciadas, a despeito de tantos decretos da inutilidade destes gestos. Pois, como ressalta Didi-Huberman, "Seria ainda preciso reconhecer a essencial vitalidade das sobrevivências e da memória em geral quando ela encontra as formas justas de sua transmissão" (2011, p. 153). Uma posição de quem se nega a desistir. Lugar em que localizamos Yellow Fever.

\section{Trajetória: arte, identidade e memória}

Para Beatriz Furtado, mesmo que o cinema tenha se consolidado enquanto produto industrial "e, portanto, [se] submetido à lógica e às regras do mercado cinematográfico, jamais perdeu sua capacidade de experimentação e a radicalidade da arte, criando para si diferentes campos, circuitos e movimentos" (FURTADO, 2014, p. 27). Assim, a despeito de ter sido Hollywood quem definiu as formas dominantes de produção, realização e distribuição, a história do cinema nunca ficou à margem dos desenvolvimentos tecnológicos. O percurso, não raro, incluiu desafios ao modelo hegemônico e trouxe à narrativa cinematográfica e seu dispositivo o imperativo de diálogos com as outras artes. Não à toa, portanto, que entre as citadas experimentações esteja uma relação fértil com as artes plásticas, particularmente a partir dos anos 1960, quando se adensa o entrelaçamento da arte e da tecnologia em uma perspectiva de estender para as artes visuais experimentos que já mesclavam dança e teatro, corroborando o que Ruch define

5 As citações diretas da fala de Ng'endo Mukii foram registradas em evento realizado em 8 de dezembro de 2018, no Museu da Maré, Rio de Janeiro, intitulado Uma Conversa com Ng'endo Mukii. O evento foi realizado pela Rede eVoices (http://evoices.cemp.ac.uk/) em parceria com o Instituto Goethe e também incluiu a exposição de mais de 700 imagens da citada animação Retrato de Marielle Franco. 
como "nascimento da arte performática" (2006, p. 30). Tais trânsitos impactaram a relação do vídeo com a arte e vice-versa, naturalizando, cada vez mais, as hibridizações de linguagem. Em Yellow Fever, o reconhecimento da potência artística deste caminho ancora-se tanto na trajetória da cineasta - que, também designer, afirma trabalhar, preferencialmente, com animação documental -, quanto no percurso da sua formação. Esta inclui pesquisas estéticas que resultaram no conceito de taxidermia fílmica que, segundo $\mathrm{Ng}^{\prime}$ endo Mukii, permite representar sua herança cultural ao mesmo tempo que expressa sua resistência às narrativas coloniais que são sempre pautadas pelos estereótipos e pelo racismo.

Eu estava trabalhando na minha dissertação da Royal College of Arts, comparando o processo de taxidermia com o início do cinema etnográfico. As duas práticas envolvem um ato de exclusão, de edição, a fim de apresentar espécies indígenas como ícones em um contexto estrangeiro. Em uma pose. Ambos dependem da ilusão do parecer "real" ou do "realismo" para serem convincentes (MUKII, 2018).

Conforme Mukii, esta proximidade traz à tona uma ironia: assim como o taxidermista deve provocar nas pessoas a ilusão do animal vivo, nos filmes etnográficos os indígenas ${ }^{6}$ devem sempre ser apresentados como já estando mortos ou em uma situação em que eles e o modo como vivem estão muito próximos de desaparecer, apesar de estarem plenos e vivos. Uma das matrizes dessa reflexão vem de um momento da sua infância quando encontrou na estante do seu pai o livro Os Últimos Africanos:

Nestas páginas aprendi o que significava ser um africano. Aprendi que apesar de existirem milhões de nós, estávamos à beira da extinção... Eu sofri, em silêncio, o falecimento do meu povo, que eu nunca conheci, e me arrependi por ter nascido depois da nossa era de beleza e nobreza selvagem (MUKII, 2018).

Mais de 20 anos depois de ter segurado pela primeira vez o livro citado, ela se deparou com a exposição Antes que eles morram, no MoMA (Museu da Arte Moderna de Nova York), o que mobilizou suas memórias e a levou a se confrontar com a imagem que tinha de si e se interrogar sobre como era vista. O embate a fez questionar o quanto a mídia era tendenciosa em relação aos ideais ocidentais de beleza. Reflexão que a levou à própria infância, tantas vezes atravessada pelo movimento de adequação a estes ideais. Como coloca Didi-Huberman (2011, p. 30) "Quando a noite é mais profunda, somos capazes de captar o mínimo clarão, e é a própria expiração da luz que nos é ainda mais visível em seu rastro, ainda que tênue". O insight, portanto, fez Mukii observar-se e retomar suas vivências. Um momento que, para ela, marca o começo do seu filme.

Ao procurar reescrever sua história, a cineasta investe na estratégia que Grada Kilomba, quando interrogada por Djamila Ribeiro, define como parte do processo de

6 A cineasta adota o termo indígena como similar a nativo. Deste modo, irmana, também, os massacres e genocídios na América, África e Austrália, por exemplo. 
descolonização. Isto é, não se negar a formular questões e, sim, desdobrá-las: "Parte do processo de descolonização é se fazer essas questões. É perguntar, às vezes não ter a resposta, e fazer novas perguntas. Quando eu trabalho, sou a favor de criar novas questões e não necessariamente de encontrar respostas" (RIBEIRO, 2018, p. 109). Interrogações que em Yellow Fever materializaram a memória, tornaram presente o que jazia submerso no cotidiano, e reengendraram uma estratégia argumentativa que era documental, mas que pretendia ser reconhecida para além da ideia de uma experiência única. Por isso o investimento na animação, pois esta "não está vinculada à imagem real e o seu uso criativo é capaz de emular emoções e experiências humanas, até mesmo em um nível fantástico. O conteúdo é mantido como universal. Qualquer pessoa pode se identificar com ele" (MUKII, 2018).

A opção, de certo modo, criou no vídeo um jogo entre a sociabilidade pública, quando "os indivíduos não são seres independentes que modelam seus próprios destinos e confrontam uma sociedade cujos valores eles são livres de aceitar ou rejeitar" (MOSCOVICI, 2015, p.262), e a dimensão privada, que desenha um percurso marcado por uma sucessão de situações particulares cuja unidade existe na e pela memória. No entanto, como lembra Moscovici (ibidem, p. 207-212), o tempo, na sociedade atual, está atravessado pela extensão da mídia (visual, escrita e áudio), o que obscurece as representações sociais na medida em que o conhecimento e a própria memória se dão, mais e mais, pelas representações de representações, mutilando, não raro, as referências diretas. Uma contaminação que reverbera no processo criativo, pois as categorias (morais, éticas), e os sentidos que cada um de nós escolhe conferir às pessoas, às propriedades e às coisas, nunca são estanques e modificam-se pelo impacto do tempo e das experiências, isto é, pela impregnação do presente sobre o passado, que modifica o olhar sobre a temporalidade que já não existe mais, esta que já foi impactada pelo processo inexorável de esquecimento que causa perda, desvanecimento e diluição da memória, mesmo a mais contundente (ASSMANN, 2011). Perspectivas que ganham um caráter especial se concordarmos com Butler (2017) quanto ao imperativo ético que uma narrativa do eu impõe, já que há uma eminência de fracasso "quando o 'eu' apresentado na primeira frase como voz narrativa não pode fazer um relato de como se tornou um 'eu' que pode narrar a si mesmo ou narrar esta história em particular" (ibidem, p.89). Tais armadilhas, claro, margeiam Yellow Fever, e a nossa tentativa é compreender como o processo criativo lida com elas.

\section{Yellow Fever: linguagens imbricadas}

As primeiras imagens de Yellow Fever apresentam planos rápidos e intensos, com a câmera colada à pele de um corpo que, exposto na tela de forma fragmentada, pulsa. Há um trabalho de design de som que reforça o ritmo da pulsação, colando-o à temporalidade dos batimentos cardíacos. A sequência dura cerca de 10 segundos e não prepara para a cena 
seguinte que estabelece o nível informativo do filme como um contraponto à performance anterior, desenhada sensorialmente e apresentada em instantâneos. Ou seja, já aqui vemos uma inversão: o que é captado realisticamente é trabalhado no nível do sensível, prevalecendo a expressão, a densidade, o jogo da edição, enquanto a animação, de traços simples, com poucas nuances de cores e sem jogo de luz, incorpora referências do real, tais como quadros e produtos estéticos que reforçam a naturalidade do embelezamento à moda branca, isto é, a negação dos traços identitários do negro. Outro elemento pictórico da sequência animada são as mãos claras da cabeleireira, destacadas no canto direito alto (de quem olha), cujo tom é idêntico à pele das mulheres que ilustram a parede dos fundos do local (Figura 1). É esta cabeleireira que a voz da cineasta apresenta como mkorogo (em Suaili: lento), pessoas identificadas assim por descolorirem a pele, enquanto Mukii é caramelo e a irmã, chocolate.

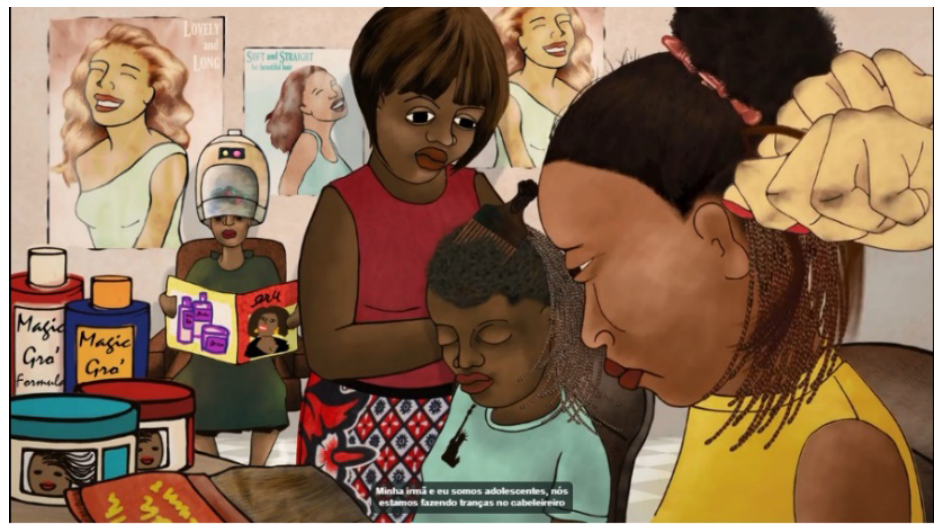

Fig. 1. Frame de Yellow Fever. As irmãs vão à cabeleireira para trançar os cabelos

Este início do vídeo já estabelece como será sua estrutura narrativa, que vai alternar a animação e a performance, sendo esta captada em um espaço cru e fechado que valoriza o gestual do corpo exposto em seu diálogo com a câmera que o percorre de vários modos. Tal deslizar projeta a autoimagem da cineasta, em pleno ativismo contra os ideais ocidentais de beleza, que ela denuncia serem impostos pelo colonialismo e se perpetuarem na mídia, afetando as pessoas e naturalizando a busca pelo padrão branco, mesmo sendo esta opção uma violência contra o próprio corpo. Fabula-se, assim, um território fecundo que se abre a uma infinidade de percepções acentuadas pelo jogo da continuidade, muitas vezes resolvida a partir do corpo. Por exemplo, os braços fortes da cabeleireira apresentados frontalmente se espelham no mesmo enquadramento da performance: ambos em primeiro plano, sob um áudio que, seco, reforça o elo entre as duas personagens. No entanto, ao fundo, a diferença entre os dois enquadramentos se 
estabelece, inequívoca (Figura 2). Uma opção que consolida e dá consistência à narrativa, potencializando a denúncia e ampliando o impacto do áudio documental.
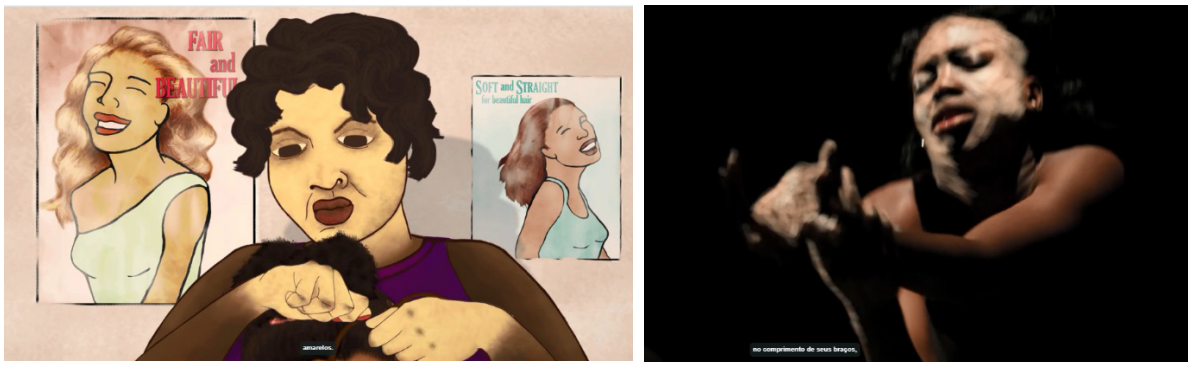

Fig. 2. Frames de Yellow Fever. Sequência que articula a continuidade narrativa a partir do destaque aos braços, ambos escuros, já que a cabeleireira só teve dinheiro para descolorir suas mãos e rosto.

Na combinatória lógica da exterioridade do corpo revelado pela performance, a cineasta projeta, também, outras simbologias. Sobre o contorno em curvas da performer, sobrepõe os cenários africanos, mapas e outras imagens, em procedimento metonímico que evoca a figuração do continente negro com suas marcas da colonização. Há, ainda, alguns rápidos momentos de ilustração, em que símbolos icônicos, já amplamente trabalhados na cultura de massa (o que facilita a imediata identificação), corroboram o que é sutil e poeticamente dimensionado pelo áudio, também este construído em tópicos-sínteses. Todos estes caminhos remetem ao controle das imagens automáticas que, conforme Couchot (2001), interessa a artistas que investigam as possibilidades das linguagens e procuram distanciar a obra da analogia com o real. Ng'endo Mukii, em Yellow Fever, investe neste percurso híbrido, submetendo as imagens à narrativa que quer construir, e optando por ter como fio condutor um áudio relativamente primário. Assim, estabelece quatro níveis de sua presença na obra: como narradora que aciona a memória; como personagem em cena; como intérprete criadora e crítica destas lembranças e testemunhos que são contextualizados na amplitude social do seu país colonizado e, ainda, como uma repórter da própria intimidade familiar, ora em cena, ora fora de quadro.

Com esta bricolagem subjetiva, em que observa e se expõe à observação, Mukii mixa níveis de representação que são marcados pela técnica acionada pelos cenários-espaços e pelo tempo que não fica prisioneiro apenas da sua memória. Esta escolha é interessante porque se flutuássemos apenas pelas recordações, estas, por mais fortes que fossem, poderiam ser percebidas somente como marcas de um tempo passado. No entanto, sua escolha de gravar o áudio da conversa que teve com uma menina - Abby, sua sobrinha - e também a de incluir um diálogo com sua mãe, redimensiona esta temporalidade, estabelecendo o longo e contínuo laço com o colonialismo e suas fortes e violentas permanências. Vale mencionar aqui que há uma única data apresentada no vídeo, que é o ano de 1994 (período em que a artista frequenta a Escola Missionária para Jovens Garotas), 
onde é possível inferir a existência de um manual de boas maneiras desligado do universo cultural das jovens quenianas. A explícita referência assume, deste modo, um viés duplo, ao demarcar, primeiro, uma ética da representação do passado "(...) que implica a nossa dívida com ele e com os mortos" (SELIGMANN-SILVA, 2003, p. 64). E, segundo, por revelar, ao mesmo tempo, os limites e a impossibilidade de abarcá-lo como totalidade.

São estas intercessões que clarificam valores e contribuem para uma percepção que busca o extracampo, reencontrado nas performances. O recorte instigante torna tangível o que pode ser percebido como devaneio que se apresenta para o debate ético, crítico e afirmativo da cultura e dos corpos negros. Posiciona-se, deste modo, à contrapelo do código hegemônico, rompendo, claramente, com a estratégia da naturalização e cerzindo o território fecundo da interioridade que ousou se interrogar, apresentando sua trajetória de dor, sua disposição ao levante e convocando a que se problematize a manutenção do corpo como morada estrangeira, colonizada. Nesta fusão das recordações doloridas com as imagens-intérpretes não só da dor, mas também da indignação e da disposição de reverter o massacre a que os corpos negros são submetidos, a diretora abandona a primeira pessoa, afrouxando a relação autobiográfica e estabelece um estado intermediário entre o testemunho e a interpretação, agenciando a intersubjetividade do tecido social. O que revela o esforço de também documentar, de forma elástica, o entorno no tempo e no espaço, confirmando a permanência da cultura sobreposta à política pública de proibição da venda do creme que promete embranquecer a pele negra ${ }^{7}$.

Tracejar o amplo percurso da subjetividade no cinema documentário contemporâneo inclui questionamentos relacionados à projeção, ego, identificação e imaginário, o que antes pensava-se restrito à ficção (RENOV, 2004). Em uma produção que se identifica como animação documental, caso de Yellow Fever, consideramos que a mesma lógica se aplica, em especial pelos trânsitos entre linguagens, como já apontamos. O risco que se corre é o de criar zonas de incompreensão delineadas pelo excesso de fragmentação somado ao tempo curto da obra. Diante deste horizonte, vale perguntar, junto com Butler (2017), se é possível identificar no vídeo o quanto o relato do eu se desenha a partir do desejo de uma relação com determinada recepção. E, para além deste desejo, há a própria formação deste eu que se inicia na infância quando se é um "ser que já foi tocado, movido, alimentado, modificado, colocado para dormir, estabelecido como sujeito e objeto de fala" (ibidem, p. 93).

É claro que encontrar respostas na obra implica uma relativa especulação sobre as situações autobiográficas, uma vez que o que se apresenta como registro ganha força e status de verdade, reforçando o caráter documental da animação. Por isso, a presença de Abby, a sobrinha, em registro que se estabelece pela firme disposição de romper com os estereótipos e também a de documentar a animação ao parasitá-la com imagens

7 Em maio de 2001 o governo do Quênia proibiu a comercialização do produto. Uganda, logo depois, fez o mesmo. (UGANDA..., 2001). 
oriundas da televisão, materializa o sonho impossível da infância modelada pela beleza da branca (Figura 3). A presentificação deste código estético desde a cena na cabeleireira e a confirmação de seu potencial de naturalização no diálogo da cineasta com sua mãe corroboram o testemunho de Mukki. "Uma só pessoa é um indivíduo, uma expressão de liberdade, ao passo que duas pessoas são uma comunidade, uma expressão de controle social", lembra Boaventura Santos (2014, p.176), referindo-se à importância de se acionar uma testemunha para viabilizar a história.

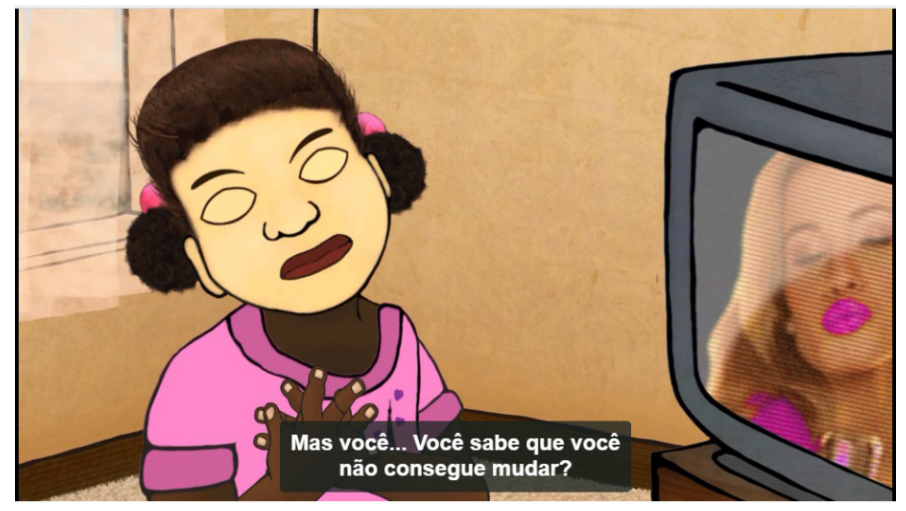

Fig. 3. Frame de Yellow Fever. A sobrinha da cineasta, Abby diz, sem autocensura, que gostaria de ser norte-americana: "Se eu fosse americana, eu seria branca branca branca e eu adoro ser branca! Eu adoro...".

Ambas sequências convocam posicionamento ativista capaz de estabelecer relação entre as reflexões interiorizadas e a ação de expressá-las na sua identidade de cineasta e artista. A postura exclui a situação de vítima e permite superar o desafio apontado por Butler (2017) quanto à dificuldade de se relacionar ética e crítica social em função das normas sociais estarem vinculadas à origem da existência de cada um, situação que impede tematizá-las plenamente: "Sou interrompida por minha própria origem social, e por isso tenho de encontrar um jeito de avaliar quem sou deixando claro que sou da autoria daquilo que me precede e me excede, e que isso, de maneira nenhuma, me exime de ter de relatar a mim mesma" (idem, p.107). Yellow Fever, em sua estratégia narrativa de múltiplas vozes, incluindo a da cineasta, ecoa esta posição fertilizada pelas pontes artísticas que viabiliza ao criar níveis narrativos distintos em termos de linguagem. Um controle fortemente possibilitado pela própria herança dos múltiplos diálogos da arte com a tecnologia - como os tantos citados por Popper (2001, p. 201) e outros pesquisadores -, que fundamentaram experimentações e articularam viabilidades estéticas, redimensionando os meios de expressão tradicionais. O próprio desenvolvimento da tecnologia digital conferiu extrema maleabilidade à imagem. Algo que $\mathrm{Ng}^{\prime}$ endo Mukii incorpora, manipulando sem pudor os recursos captados pela câmera. 
Com esta abundância de possibilidades, seu dilema talvez tenha sido condensar as críticas pretendidas em signos potentes. Ao fabular o real imediato originado pelo áudio das entrevistas e entrecruzar seu domínio técnico da animação com o devaneio potente da performance, sendo que esta não se limita aos movimentos, ao gestual, a realizadora também submerge no fluxo da indignação e na potência da memória. Não esquecendo, ainda, da imaginação que "quer sempre comandar. Ela não poderia se submeter ao ser das coisas. Se aceita as suas primeiras imagens, é para modificá-las, exagerá-las" (BACHELARD, 2001, p.23). Ou, ousamos dizer, a imaginação é acionada em Yellow Fever para romper com o cativeiro da autoimagem corporal aprisionada em um modelo de dor, alicerçado pela lógica de um delírio cruel de dominação aparentemente sincrônica ao desejo coletivo, ignorando-se o quanto este foi moldado pela violência. Não à toa, ao final do seu libelo, a cineasta invade o espaço performático com os simbólicos cremes de descolorir (Figura 4), causando um efeito próximo do kitsch, que não se impõe porque, a esta altura, a cumplicidade em relação à denúncia faz desejar que tudo exploda, como se fosse possível estilhaçar a opressão.

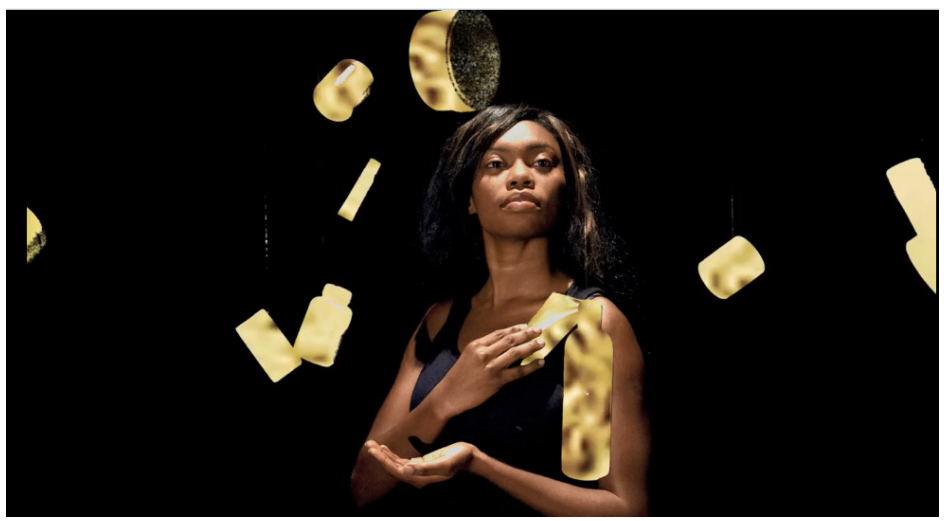

Fig. 4. Frame de Yellow Fever. O creme de descolorir entra em cena.

\section{Considerações Finais}

Se falamos em cumplicidade é preciso, talvez, apontar como ela se estabelece na relação com Yellow Fever, para além do pertencimento (ou não) ao mesmo território da cineasta. É óbvio que há - hoje circulando na direção oposta aos discursos que escamoteiam e/ou negam o racismo, o machismo e todas as variáveis de perseguição à diversidade humana (gênero, sexo, raça) - um amplo leque de resistência no qual o audiovisual se apresenta. Nesta chave, a memória tem peso, especialmente quando centrada no núcleo da infância pois esta, conforme Bachelard (2018), une mais intimamente o real ao 
imaginário, e tende a ecoar lembranças que, idealmente, devem partilhar belezas e acionar vínculos afetivos, incluindo a admiração pelo próprio passado.

Quando, na solidão, sonhando mais longamente, vamos para longe do presente reviver os tempos da primeira infância, vários rostos de criança vêm ao nosso encontro. Fomos muitos na vida ensaiada, na nossa vida primitiva. Somente pela narração dos outros é que conhecemos a nossa unidade. No fio de nossa história contada pelos outros, acabamos, ano após ano, por parecer-nos com nós mesmos. Reunimos todos os nossos seres em torno da unidade de nosso nome. (BACHELARD, 2018, p.93)

Trata-se de uma evocação, digamos, positiva, onde há pouco espaço para marcas de um calendário violento, excludente, cruel. Mas esta não é a realidade da biografia de Mukii, que nos apresenta a volta à infância em uma estética de contraste: enquanto a imagem harmônica da animação realizada com traços distantes da mimese e com técnica próxima aos códigos do desenho infantil remete à leveza e à percepção de um mundo familiar protegido e sem tensões, o áudio conclama postura que desmonta qualquer possibilidade de placidez. "Não basta desobedecer. É urgente, também, que a desobediência a recusa, o apelo à insubmissão - se transmita aos outros no espaço público", coloca Didi-Huberman (2017, p. 370), reproduzindo, com suas palavras, talvez centenas de outras conclamações à revolta, à luta, à denúncia, que enfileiram-se ao longo do tempo nesta, até hoje inevitável, opressão homem-homem, observada individual e coletivamente. É este o lugar primeiro de Yellow Fever que assume, como Seligman-Silva (2003) e tantos outros, que a memória nunca é tão somente do indivíduo, mas está sempre inserida em um determinado contexto coletivo.

No contexto contemporâneo feminino sabe-se que "O investimento de tempo e de recursos financeiros na aparência expõe a permanência de padrões desiguais de gênero" (BIROLLI, p. 117), mantendo-se as expectativas da sociedade no sentido de que cabe à mulher investir em sua aparência, sendo esta desenhada por um ideal que não dialoga com a realidade da maior parte da população. Em especial com o acréscimo do fator raça. Por isso, "o ideal de beleza implica sofrimento, baixa autoestima e pode ter efeitos concretos na saúde das mulheres" (ibidem, p. 118). E aqui não vale simplesmente argumentar, com Elias \& Scotson (2000, p. 199), que as "desigualdades entre grupos e indivíduos estão entre as marcas distintivas recorrentes das sociedades humanas". Pois, se ainda há certos dilemas que afligem o esforço de modelar a matéria tantas vezes incoerente, ambígua ou ausente dos sonhos de mudanças e seus vestígios, para nós é na concepção e fruição da arte, que investe no desassossego, na inquietude, que será possível reverberar o reencontro da identidade e da reconstrução de uma outra memória.

Assim, vale citar Rezende (2013, p. 126) quando este lembra que "Quando se fala, por exemplo, em realidade - especialmente para apontar sua relação com o documentário - tende-se a ignorar a dimensão virtual dos objetos, acontecimentos e situações tratados, considerando-os reais porque existem". Isto é, na inversão pictórica proposta por Mukii 
já não há possibilidade de se encontrar a origem pura, ou alguma totalidade que permita uma completude no círculo fechado da obra. O que existe é o esforço da criação, da viabilização de um projeto a partir de reminiscências, lembranças, falas e imagens embaralhadas e encharcadas do seu real. Celebrar esta poética que entrelaça interpretaçãoexpressão da performance à competência da criação animada, incluindo o roteiro, mescla a imprecisão da vida ordinária às matrizes da história ainda necessária. Também reverencia as concepções que investem no rompimento das estabilidades construídas sob o peso do esmagamento daqueles que se postam afinados a uma nova poética do conhecimento, pautada pela exclusividade da análise, da abstração, pois “(...) para constituirmos um conhecimento vivo, é preciso ir além das fragmentações e dos especialismos que impedem a interpretação compreensiva. É preciso, também, atravessar o deserto dos conceitos abstratos e retornar à vida e às coisas" (ANTÔNIO, 2009, p. 20). Ou, juntando-nos a Angela Davis (2018, p. 43-56), dizemos com ela que "precisamos falar de mudança sistêmica".

Citar tão rapidamente Angela Davis significa, aqui, assumir uma postura que, de certo modo, acompanhou toda a construção deste texto: o reconhecimento de que ele é, no máximo, a contribuição de uma percepção da obra sem qualquer pretensão de totalidade. Especialmente agora quando, felizmente, os espaços conquistados por artistas e pesquisadoras negras configuram a constelação urgente, necessária e legítima que por tanto tempo e por longo espaço esteve ausente nos estudos da arte, particularmente nos estudos historiográficos. Portanto, nossa pretensão alinha-se tão somente às discussões possíveis do recorte proposto. O que não excluiu inúmeros impasses e maior clareza quanto à própria bibliografia que utilizamos em nossas pesquisas. Não à toa. Vozes como a de Stephanie Ribeiro, entre outras, lembram o quanto, na história do feminismo, as narrativas da diversidade, especialmente as de raça e classe, foram sempre silenciadas: "Por isso, a nossa narrativa nasce desse recorte político no qual não somos todos iguais, pois esse debate privilegia a mulher branca como única sujeita realmente contemplada em diversas frentes, discussões e debates" (2018, p. 263). Reproduzir e concordar com este diagnóstico impõe-se como a política justa, a nosso ver.

Mas, retomando nosso foco depois de esclarecer esta questão vital da nossa proposta, voltemos ao que o vídeo de Mukii nos traz a partir da cadência rítmica que propõe na alternância entre os dois níveis centrais da narrativa - a animação e a performance. Para nós, em resumo, a obra principalmente refina um diagnóstico que, como dito, não é pioneiro, mas ganha fôlego exatamente pela aderência ao biográfico sem se perder nele, e pelo investimento seguro no trânsito das linguagens. Há nesta escolha de representação a coerência argumentativa e ética, necessárias à empatia e à adesão. Diante de um vazio gigante que predominou na ocultação da barbárie colonial, seu discurso audiovisual reelabora a tônica da necessária diversidade e do respeito à história cultural originária de cada país. Perfura, deste modo, um padrão hegemônico falido e alicerça uma estratégia singular de representação que corrobora o esgarçamento de gênero, somando-se, deste 
modo, a outras propostas experimentais às quais, o cinema curto, em especial, não tem se negado. Afinal, tantas escolhas potentes e generosas com a própria certeza de que o ativismo é necessário, traduz a "aventura do sonho exposto à correnteza", como escreveu Cecília Meireles (2017, p. 216).

Denise Tavares da Silva é professora e pesquisadora da Universidade Federal Fluminense no Programa de Pós-Graduação Mídia e Cotidiano, que coordenou de 2015 a 2019, e no curso de Comunicação Social. É doutora em Integração Latino-Americana e mestre em Multimeios.

denisetavares51@gmail.com

\section{Referências}

ANTÔNIO, S. Uma nova escuta poética da educação e do conhecimento: Diálogos com Prigogine, Morin e outras vozes. São Paulo: Paulus, 2009.

ASSMANN, A. Espaços da recordação: Formas e transformações da memória cultural. Campinas/ SP: Editora da Unicamp, 2011.

BACHELARD, G. A Terra e os Devaneios da Vontade: Ensaio sobre a imaginação das forças. $2^{\text {a }}$ ed. São Paulo: Ed. Martins Fontes, 2001.

A poética do devaneio. $4^{\mathrm{a}}$ ed. São Paulo: WMF Martins Fontes, 2018.

BIROLI, F. Autonomia, Dominação e Opressão. In: MIGUEL, L. F.; BIROLI, F. Feminismo e Política. São Paulo: Boitempo, 2014. p. 109-122.

BUTLER, J. Relatar a si mesmo: Crítica da violência ética. Belo Horizonte: Autêntica Editora, 2017.

COUCHOT, E. Da Representação à Simulação. In: PARENTE, André (Org). Imagem Máquina. A Era das Tecnologias do Virtual. $3^{\text {a }}$ ed. $1^{a}$ Reimpressão. São Paulo: Editora 34, 2001. p. 37-48.

DAVIS, A. A Liberdade é uma luta constante. São Paulo: Boitempo, 2018.

DIDI-HUBERMAN, G. Sobrevivência dos vaga-lumes. Belo Horizonte: Editora UFMG, 2011.

(Org.). Levantes. São Paulo: Edições Sesc, 2017.

ELIAS, N.; SCOTSON, J. L. O Estabelecidos e os Outsiders. Rio de Janeiro: Zahar, 2000.

FURTADO, B. Um campo difuso de experimentações. In: GONÇALVES, O. (Org.). Narrativas sensoriais. Rio de Janeiro: Circuito, 2014.

MEIRELES, C. Poesias Completas - 2 volumes. São Paulo: Global Editora, 2017.

MOSCOVICl, S. Representações Sociais - Investigações em psicologia Social. $11^{\text {a }}$ ed. Petrópolis: Vozes, 2015.

POPPER, F. As imagens artísticas e a Tecnociência (1967-1987). In: PARENTE, A. (Org.). Imagem Máquina. A Era das Tecnologias do Virtual. $3^{\mathrm{a}}$ ed. $1^{\text {a }}$ Reimpressão. São Paulo: Editora 34, 2001. p. 201-213. 
RENOV, M. The Subject of documentary. Minnesota: University of Minnesota Press, 2004.

REZENDE, L. A. Microfísica do Documentário - Ensaio sobre Criação e Ontologia do Documentário. Rio de Janeiro: FAPERJ/Azougue, 2013.

RIBEIRO, D. Quem tem medo do feminismo negro? São Paulo: Cia das Letras, 2018.

RUSH, M. Novas mídias na arte contemporânea. São Paulo: Martins Fontes, 2006.

SANTOS, B. S. O direito dos oprimidos. São Paulo: Cortez, 2014.

SELIGMAN-SILVA, M. Reflexões sobre a memória, a história e o esquecimento. In:

(Org.).História, memória, literatura: O testemunho na era das catástrofes. Campinas: Ed. Unicamp, 2003. p. 59-88.

UGANDA vai proibir uso de cremes clareadores de pele. Folha Online. São Paulo, 14 ago. 2001. Disponível em: <https://www1.folha.uol.com.br/folha/reuters/ult112u4618.shtml>. Acesso em: 1 mar. 2020.

\section{Videografia}

RETRATO de Marielle Franco. Coordenação de animação de Ng'endo Mukii e Paula Callus. Nairobi, Quênia: eVoices, 2018. (1'57").

YELLOW Fever. Escrito e dirigido por Ng'endo Mukii. Londres: Royal College of Arts, 2012. (6'48")

Artigo recebido em 22/11/2019

e aprovado em 31/12/2019. 